\title{
Research on Bogie Frame Lateral Instability of High-Speed Railway Vehicle
}

\author{
Chen Wang, ${ }^{1}$ Shihui Luo, ${ }^{1}$ Ziqiang Xu, ${ }^{2}$ Chang Gao, ${ }^{1}$ and Weihua Ma ${ }^{1}{ }^{1}$ \\ ${ }^{1}$ Traction Power State Key Laboratory, Southwest Jiaotong University, Chengdu 610031, China \\ ${ }^{2}$ China Academy of Railway Sciences, Locomotive Car Research Institute, Beijing 100081, China \\ Correspondence should be addressed to Weihua Ma; maweihua2008@gmail.com
}

Received 17 November 2017; Revised 25 March 2018; Accepted 19 April 2018; Published 29 May 2018

Academic Editor: Mario Terzo

Copyright (c) 2018 Chen Wang et al. This is an open access article distributed under the Creative Commons Attribution License, which permits unrestricted use, distribution, and reproduction in any medium, provided the original work is properly cited.

\begin{abstract}
In order to find out the reason for the bogie frame instability alarm in the high-speed railway vehicle, the influence of wheel tread profile of the unstable vehicle was investigated. By means of wheel-rail contact analysis and dynamics simulation, the effect of tread wear on the bogie frame lateral stability was studied. The result indicates that the concave wear of tread is gradually aggravated with the increase of operation mileage; meanwhile the wheel-rail equivalent conicity also increases. For the rail which has not been grinded for a long time, the wear of gauge corner and wide-worn zone is relatively severe; the matching equivalent conicity is $0.31-0.4$ between the worn rail and the concave-worn-tread wheel set. The equivalent conicity between the grinded rail and the concaveworn tread is below 0.25 ; the equivalent conicities are always below 0.1 between the reprofiled wheel set and various rails. The result of the line test indicates that the lateral acceleration of bogie frame corresponding to the worn wheel-rail can reach $8.5 \mathrm{~m} / \mathrm{s}^{2}$, and the acceleration after the grinding is reduced below $4.5 \mathrm{~m} / \mathrm{s}^{2}$. By dynamics simulation, it turns out that the unreasonable wheelrail matching relationship is the major cause of the bogie frame lateral alarm. With the tread-concave wear being aggravated, the equivalent conicity of wheel-rail matching constantly increases, which leads to the bogie frame lateral instability and then the frame instability alarm.
\end{abstract}

\section{Introduction}

The instability of the railway vehicle means that the amplitude of a certain vibration type constantly increases with time when the vehicle is running at a high speed on a flat and straight track. As a result, the vehicle vibration increases; the running stability decreases; the lateral force of axle increases; a more serious hunting phenomenon occurs [13]. The instability of high-speed vehicle can cause serious damage to the line, and it also has an effect on the operation safety. Therefore, preventing the vehicle instability is of great significance in the field of high-speed vehicle research.

In the 18th century, Klingel W [4] has already proposed the definition of vehicle hunting instability. Based on an existing linear creep model, Wickens [5] has researched the relationship between worn-wheel set creep and frame stability, as well as that between wheel-rail conicity and frame stability; the results have been verified by vehicle rolling test. Cooperider N K [6] has applied the modified nonlinear creep force to the study of wheel set instability; the effects of wheelrail creep forces, longitudinal and lateral damping forces, tread slope, and wheel-rail clearance on the bogie stability have been obtained. The research of True H [7] has focused on the stability of railway vehicles; the use of nonlinear critical velocity has been proposed to evaluate the instability; the calculation method of nonlinear critical velocity has been summarized. On the basis of bifurcation theory, Polach $\mathrm{O}$ et al. [8] have proposed the stability evaluation criterion; after a large test data acquisition, the effects of equivalent conicity curves of different treads on the wheel set stability with bifurcation approach have been obtained; meanwhile, the nonlinear stability evaluation criterion has been summarized. Schupp G and Spiryagin M [9] have adopted a multibody dynamics software combined with the continuation algorithm to study the nonlinear stability of complex vehicle systems effectively. Zboinski $\mathrm{K}$ et al. [10] have studied the vehicle stability when the railway vehicle runs on curve lines and has proposed the corresponding criteria. Choi Y S [11] 
has studied the relationship between the creep/creep forces and the parameters of the primary/secondary suspension systems; by Hopf bifurcation, the direct numerical integration algorithm has been adopted to calculate the instability point of limit cycle. Based on the researches of True $\mathrm{H}$ et al., Ahmadian M [12] has studied the effect of parameters of antihunting motion damper and wheel-rail contact on the vehicle stability; the two-axis bogie has been taken as an example to analyze the creep force as well as the nonlinear wheel-rail contact characteristics; it has turned out that the nonlinear flange-rail contact could significantly increase the hunting motion of bogie. By the bifurcation method, Park J $H$ [13] has analyzed the lateral stability; the effect of vehicle suspension parameters and wheel-rail friction coefficient on the limit cycle has been studied and then verified by rolling test.

On account of the over-limit problem of frame lateral acceleration for the high-speed vehicle and according to field tests, Zhou Q Y et al. [14] have pointed out that the main reason for the frame instability in some intervals was that the equivalent conicity was excessively large. From the perspective of the instability of high-speed vehicle and the wheel-rail contact process of derailment, Sun L X [15] has investigated the limit-cycle bifurcation characteristics of the hunting motion for the high-speed vehicle and studied the key factors which affected the stability of the hunting motion. Liang S L [16] has analyzed the effect of the bogie nonlinear characteristics on the vehicle lateral stability; the matching relationship between several different treads and $60-\mathrm{kg}$ rail has been evaluated. Piao M W [17] has proposed a vehicle-lateral-stabilityanalysis method which was based on wheel-rail matching and studied the antihunting damper constraint effect on the hunting oscillation of vehicle architecture frame. By using the Hopf paradigm method, Zeng X. H. et al. [18] have studied the variable parameters of the key parameters of bogie in order to find out the key parameter value which can change the supercritical/subcritical bifurcation, so as to obtain the theoretical basis for the vehicle design in practical engineering.

The equivalent conicity, which is mainly used to evaluate the wheel-rail contact profile, is one of the most important parameters in the wheel-rail relationship $[19,20]$. After years of research, the International Union of Railways has established the standard calculation method of equivalent conicity and meanwhile has taken the wheel and the rail wear into consideration to optimize the profiles of wheel and rail. The major technical specifications are UIC518, UIC519, EN15302, etc. [21]. The above technical specifications have defined the calculation method of equivalent conicity and established the equivalent conicity limit for different running speed levels and different line conditions. There have not been relevant equivalent conicity norms and management specifications established in China yet.

In this paper, with regard to the lateral instability alarm of bogie frame for the high-speed vehicle in China, a multibody dynamics model of high-speed vehicle is developed according to the bogie structure and the wheel-rail contact characteristics. With the combination of test analysis and dynamics simulation, the relations between the wheel-rail wear and various vehicle dynamic performance are analyzed (critical

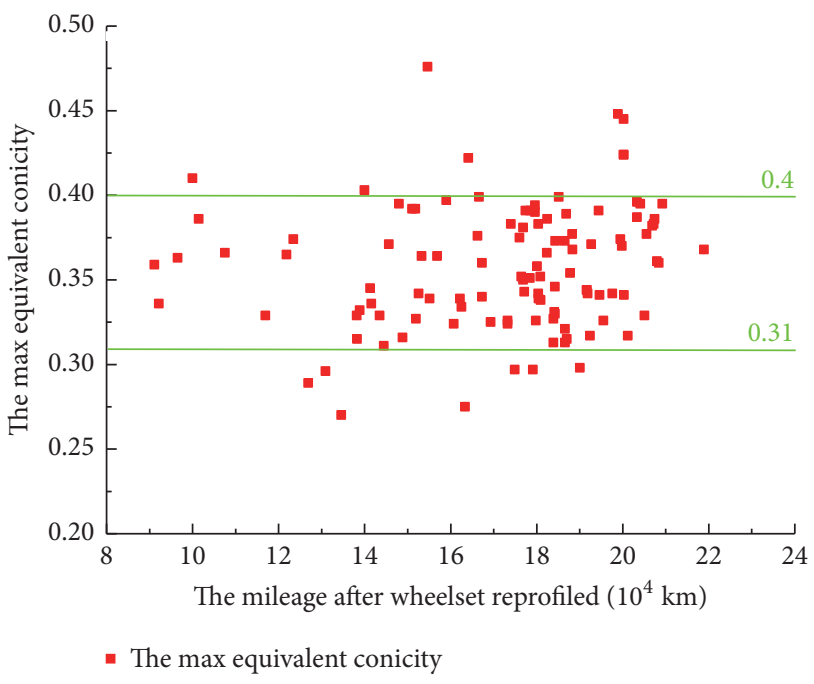

FIGURE 1: The distribution of equivalent conicities for bogie frame of lateral instability.

TABLE 1: Statistical data of bogie frame lateral alarm.

\begin{tabular}{lccc}
\hline railways bureau & $\begin{array}{c}\text { Alarm } \\
\text { frequency }\end{array}$ & railways bureau & $\begin{array}{c}\text { Alarm } \\
\text { frequency }\end{array}$ \\
\hline Shenyang & 65 & Shanghai & 9 \\
Harbin & 9 & Guangzhou & 3 \\
Beijing & 10 & Jinan & 80 \\
\hline
\end{tabular}

speed, bogie frame stability, etc.), aiming at identifying which dynamic performance is most-easily affected by wheel/rail wear. The analysis results are valuable for exploring the main cause of hollowed-wear tread in the future research.

\section{Lateral Instability Phenomenon of Bogie Frame for High-Speed Vehicle}

At the beginning of 2010, frame lateral alarms and violent shakes of car body occurred on Beijing-Tianjin high-speed railway line and Qingdao-Jinan passenger railway line. With the opening of Beijing-Shanghai high-speed railway line, Wuhan-Guangzhou high-speed railway line, Harbin-Dalian high-speed railway line, etc., the operation mileage of highspeed vehicle steadily increased. Meanwhile, the alarm of frame lateral acceleration reappeared in large numbers, which led to the stopping or the operation at a lower speed and thus had a negative effect on vehicle operation. Table 1 shows the times of the bogie frame lateral instability number for high-speed vehicles in China from January to June in 2015, which were recorded by relevant railway administrations. The number of times was up to 176 . For the purpose of solving the problem of bogie frame lateral alarm for the high-speed vehicle, a field investigation about the Harbin-Dalian highspeed railway where the bogie frame alarm occurred was carried out to learn about the bogie frame vibration.

Figure 1 shows the maximum wheel set equivalent conicities of 108 times of lateral instability alarm for the 


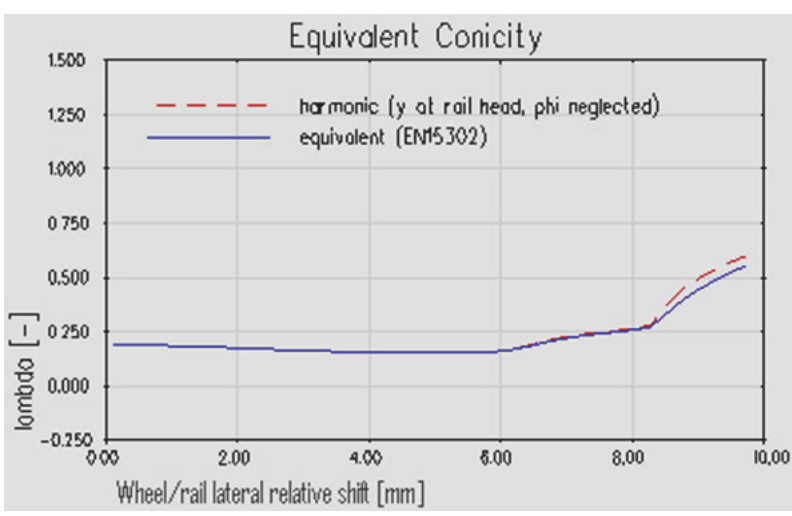

(a) The equivalent conicity curve of new wheel and rail

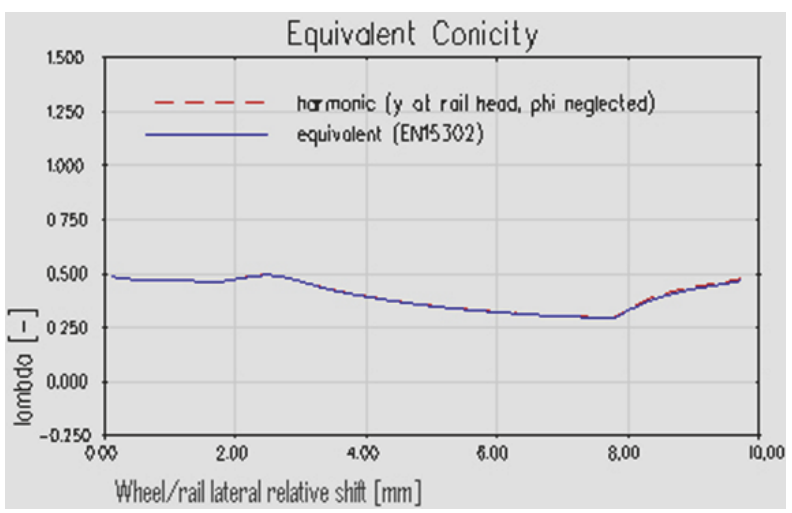

(b) The equivalent conicity curve of worn wheel and rail

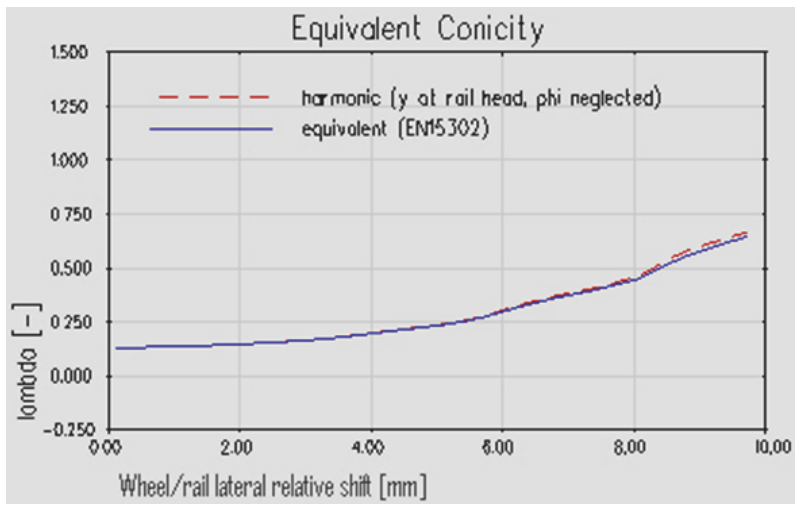

(c) The equivalent conicity curve of reprofiled wheel set and grinded rail

FIGURE 2: The equivalent conicity curve of different wheel/rail cases.

high-speed vehicle as well as the distribution of operation mileage of wheel sets after reprofiling. Based on the worn wheel set of lateral-unstable bogie and the 60-kg standard rail, the equivalent conicities were calculated. According to the calculation, for $82.9 \%$ of the wheel sets of lateral instability bogie, the equivalent conicities are between 0.32 and 0.40 . In Figure 2, curves of equivalent conicity for new wheel/rail case, worn wheel/rail case, and reprofiled-grinded wheel/rail case are presented. The figure indicates that the equivalent conicity corresponding to the worn wheel/rail case is much larger than that of the new wheel/rail case and that of the reprofiled-grinded wheel/rail case.

The vehicle stability is evaluated by bogie frame acceleration amplitude based on Testing of High-Speed Electric Multiple Unit on Completion of Construction which is a national standard of China. As required in the standard, the real-time-continuous monitoring and sampling of the lateral acceleration of bogie frame above the axle box should be carried out; the $0.5-10 \mathrm{~Hz}$ band-pass filter should be adopted for the lateral acceleration of bogie frame; on the condition that the axle lateral force, the derailment coefficient, and other indicators are all within the limit, the stability of vehicle is comprehensively analyzed. When the acceleration peak reaches or exceeds $8 \mathrm{~m} / \mathrm{s}^{2}$ for 6 consecutive times or more, the bogie can be determined laterally unstable.

\section{Lateral Instability Test of High-Speed Vehicle}

\subsection{Test Scheme and Process}

3.1.1. Measurement of Wheel-Rail Profile. The test lines are Harbin-Dalian high-speed railway line and Beijing-Harbin railway line; the latter consists of Beijing-Chinwangtao railway line and Chinwangtao-Shenyang high-speed railway line; the vehicle runs on both lines. Harbin-Dalian highspeed railway line, from Shenyang to Harbin, has a total length of $540 \mathrm{~km}$, and the design speed is $300 \mathrm{~km} / \mathrm{h}$. Beijing-Chinwangtao railway line has a total length of $294 \mathrm{~km}$, and the design speed is $200 \mathrm{~km} / \mathrm{h}$. ChinwangtaoShenyang high-speed railway line has a total length of 404 $\mathrm{km}$, and the design speed is $250 \mathrm{~km} / \mathrm{h}$.

In the section from Shenyang to Changchun (Section K850-K880) on Beijing-Harbin railway line, there were several cases of the bogie frame alarm, so it is necessary to focus on this section. Field investigations for Siping East (Section K863-K865 and Section K884-K885) on Harbin-Dalian highspeed railway line were carried out, and the relevant wheel set tread was detected. The investigation results are as follows: for Section K884-K885, rail running band of railway is relatively wide; the width is $40-50 \mathrm{~mm}$; there is offset for the light band, that is, the light band for part of the section extends to the 


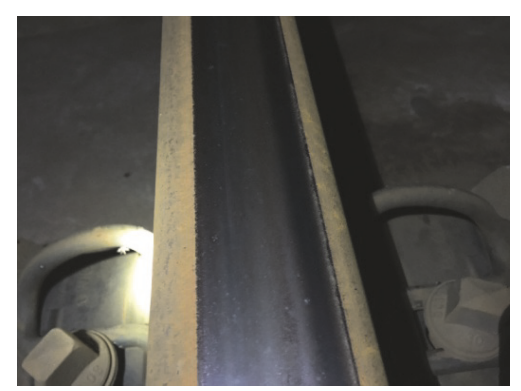

(a) Rail of wide tread wear

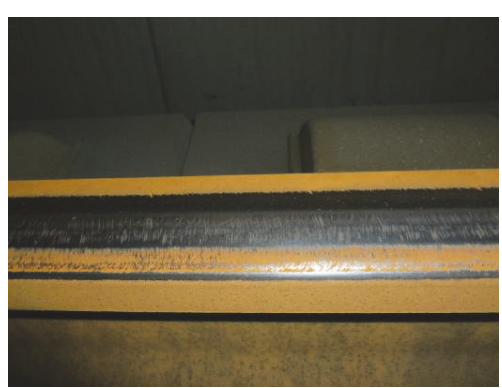

(b) Rail of gauge corner wear

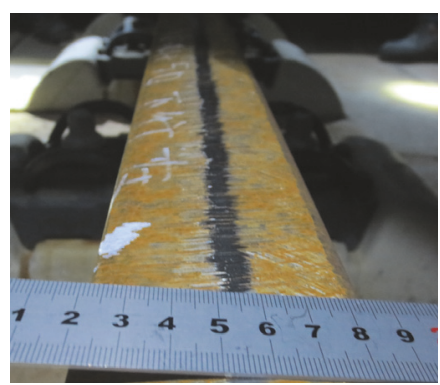

(c) Grinded rail

FIGURE 3: Field investigation.

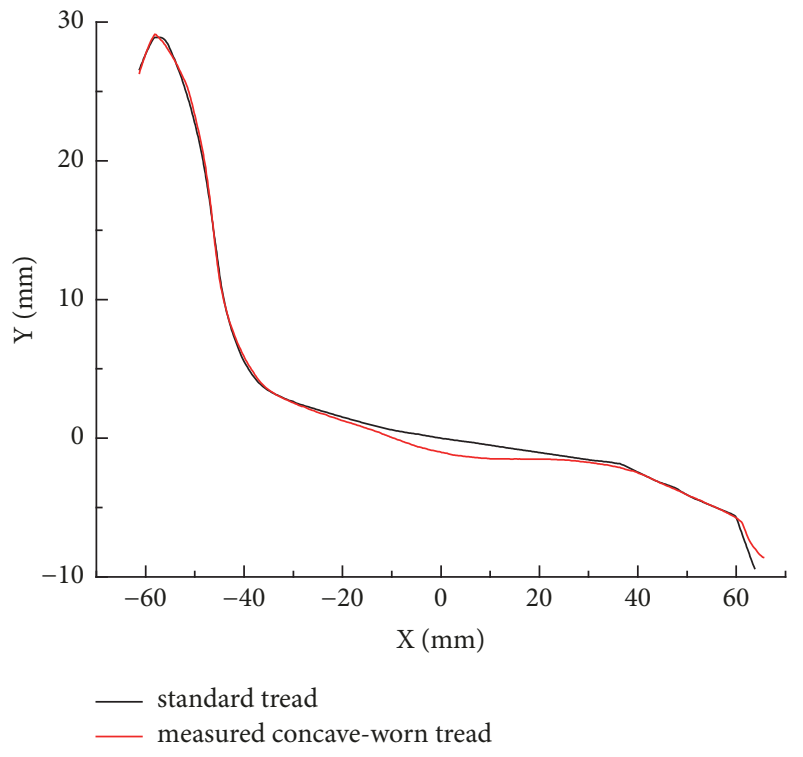

Figure 4: The measured concave-worn tread profile.

gauge corner, as shown in Figure 3(a). In addition, the distinct wear of the gauge corner was found in part of the section, as is shown in Figure 3(b). In order to compare and analyze the effect of the rail wear on the lateral stability of the vehicle frame, the uplink of the section was grinded by rail grinding train. The grinded rail is shown in Figure 3(c).

The profile of the worn tread of the test vehicle was measured by wheel set tread profile measuring instrument. The measured object was left tread of the guide wheel set where the lateral alarm occurred, for the abrasion loss of the guide wheel set is larger than other wheel sets; it was then compared with the standard tread. It was found that the tread had obvious tread-concave wear, as is shown in Figure 4. The concave wear can cause a larger matching equivalent conicity of wheel-rail, which has an effect on the lateral operation stability of bogie frame.

3.1.2. Test Method and Process. In order to analyze the effect of wheel set reprofiling and rail grinding on the lateral acceleration of bogie frame, relevant tests were carried out for the same train in some sections of Harbin-Dalian high-speed railway line. The selected sections were the uplink of Section K884-K885 where the bogie frame lateral instability occurred as well as the neighbouring downlink of Section K896-K897 where the rail was just grinded. The vibration waveform and the frequency spectrum were analyzed. Then, the wheel sets were reprofiled; the frame vibration waveform and the frequency spectrum were analyzed after the reprofiling. For the trial run after the reprofiling mentioned above, it was in the Section K215-K217 where the rail was just grinded. The test vehicle passed the unstable test line at a speed of $250 \mathrm{~km} / \mathrm{h}$; the main test content was the lateral vibration acceleration of bogie frame before and after the tread reprofiling. During the test, the sensor was installed on the frame of the 1st car; the test data was recorded in the whole process. The car number of the marshalling for the test was 16 . When the vehicle ran from Changchun to Beijing, the 1st car was the tail car; when the train ran from Beijing to Changchun, the 1st car was the head car. Besides, on Harbin-Dalian railway line, the running speed of the high-speed vehicle is $250 \mathrm{~km} / \mathrm{h}$; on Beijing-Harbin railway line, the running speed is $200 \mathrm{~km} / \mathrm{h}$.

The instability detection device includes the acceleration sensor, the $0-5 \mathrm{~V}$ voltage transducer, the DAQ (Data Acquisition) card, the DAQ software, the host, the shielded cable, and the USB cable. The device is applicable to the highspeed vehicle, whose maximum running speed is $350 \mathrm{~km} / \mathrm{h}$, to monitor the state of bogie. It can detect the lateral instability of bogie, give the alarm in time, and record the real-time state. The instability detection device mainly consists of the instability detection host and the instability detection sensor; the instability detection acceleration sensor is located on the lower side of the car body (Figures 5(a) and 5(b)); the longitudinal beam of frame is above the primary steel spring; the instability detection host is located in the car (Figure 5(c)).

Since the vehicle instability has a great effect on the running speed, the real-time monitoring system is used to monitor the bogie vibration in the whole running process. When the vehicle instability phenomenon appeared, the alarm message can be sent in time; the vehicle decreases the speed based on the alarm message. Then, the instability phenomenon can be restrained; the vehicle status information of the instability can be saved in the system, which can provide data support for subsequent troubleshooting. 


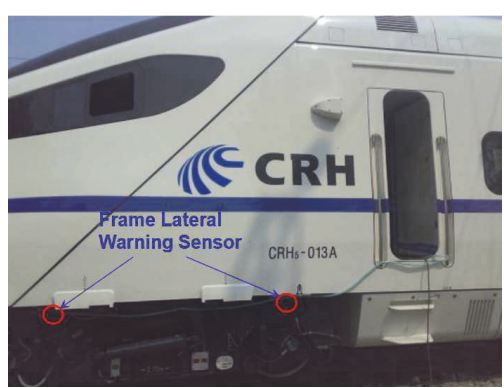

(a) The arrangement of sensor and instability detection host

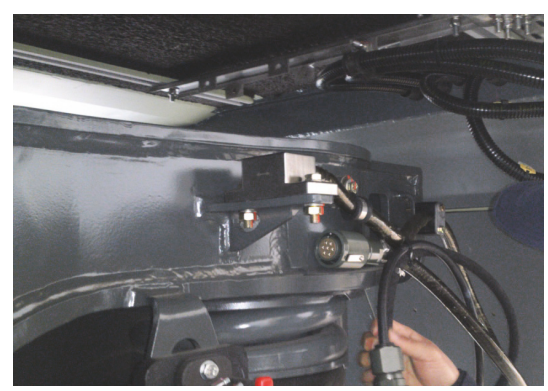

(b) The bogie frame alarm sensor

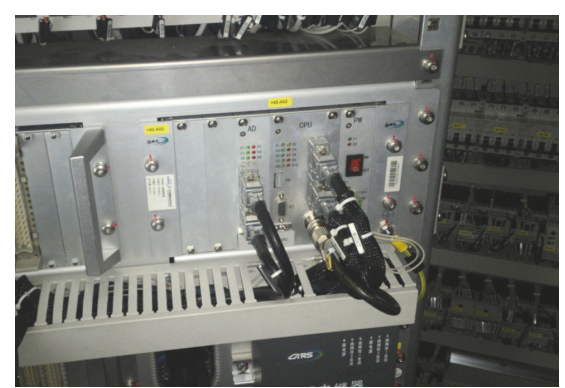

(c) The instability detection host

FIgURE 5: The alarm sensor and detection instability host.

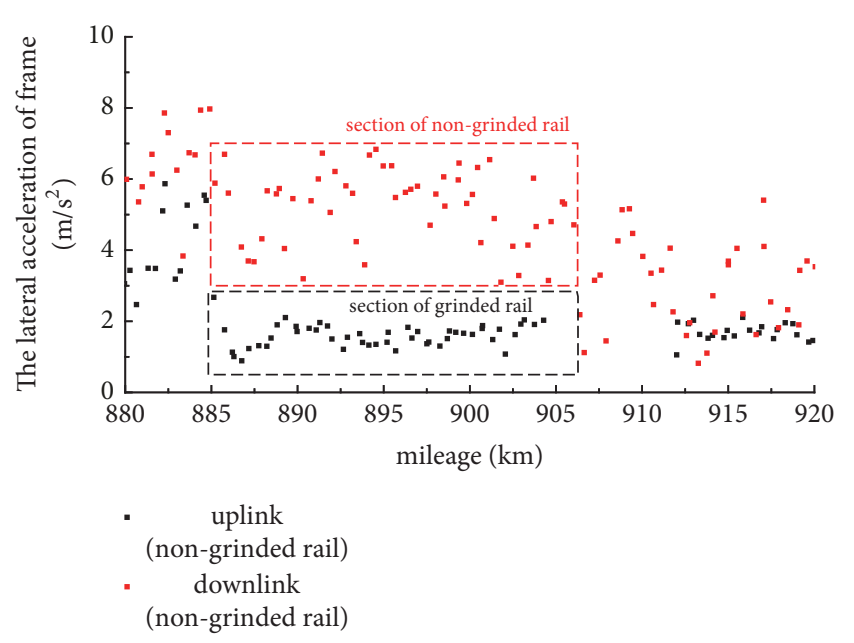

Figure 6: The lateral acceleration of bogie frame in the test section.

\subsection{Analysis of Test Result}

3.2.1. Vibration Test Result. Figure 6 is the scatter diagram of bogie frame lateral acceleration for the high-speed vehicle when passing the uplink (instability section) and the downlink (grinded section) of the test section, respectively.

Figures 7 and 8 are the waveform diagram and the spectrogram of bogie frame lateral acceleration for the test vehicle. At a speed of $250 \mathrm{~km} / \mathrm{h}$, the test vehicle passed the instability section, the rail-grinded section, and the grinded section, respectively, after wheel set reprofiling. The three tests have not been conducted on the same track section, but the track conditions and running conditions on the three selected track sections are the same. The three selected track section are all tangent track with same level of track irregularities, and the HSRS has the same running speed for the three selected track sections. Hence, the HSRS would show same vehicle system dynamic performance.

The result indicates that after the rail grinding and at a running speed of $250 \mathrm{~km} / \mathrm{h}$, the amplitude of the bogie frame vibration acceleration for uplink is reduced from $6 \mathrm{~m} / \mathrm{s}^{2}$ to $2 \mathrm{~m} / \mathrm{s}^{2}$; the dominant frequency is between 5 and $7 \mathrm{~Hz}$; the amplitude of the dominant frequency is reduced from $1.8 \mathrm{~m} / \mathrm{s}^{2}$ to $0.2 \mathrm{~m} / \mathrm{s}^{2}$. The amplitude of the bogie frame lateral vibration is significantly reduced, but there are still small periodical
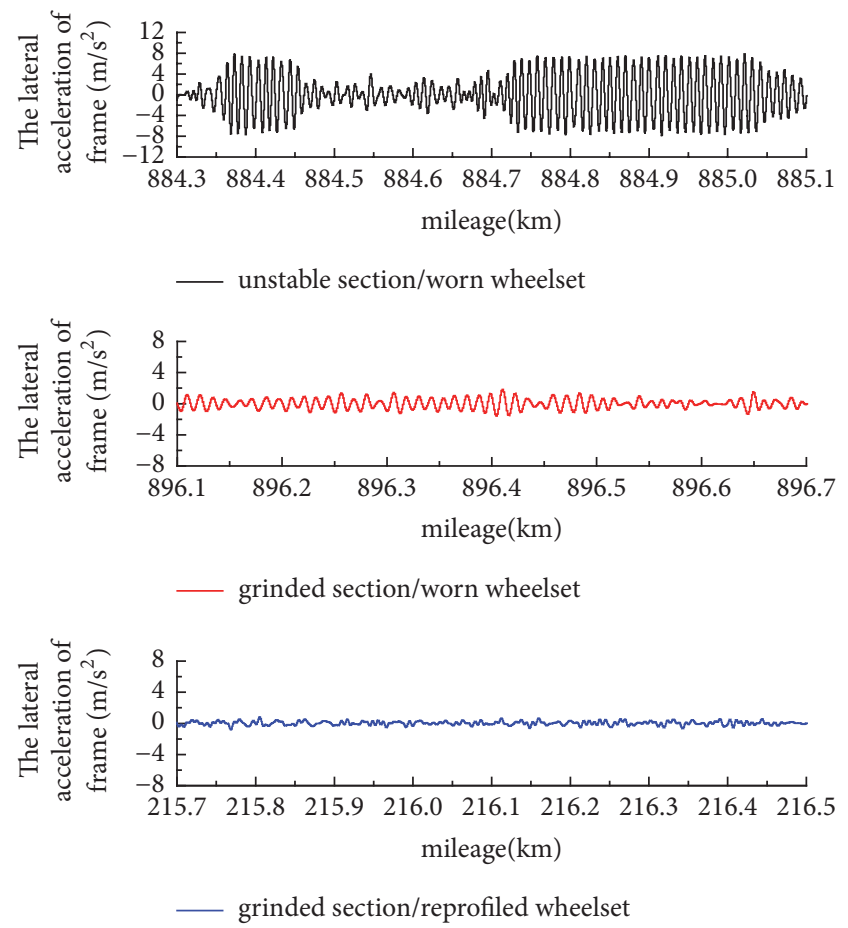

FIGURE 7: The lateral acceleration of bogie frame in different sections.

vibrations for the bogie frame in the lateral direction. For the frame of the high-speed vehicle with newly reprofiled wheels, there are irregular vibrations in the lateral direction and the amplitude is very small; the dominant frequency is beyond 0-10 Hz zone.

3.2.2. Comparison of Vibration Performances at Different Speed Stages. For the high-speed vehicle, the running speed stage in winter is $200 \mathrm{~km} / \mathrm{h}$; the running speed stage in summer is $250 \mathrm{~km} / \mathrm{h}$. The reprofiled vehicles, whose operation mileages are approximate, were chosen for the research; the vibration data of the same line at different running speeds were compared.

For the vehicles whose operation mileages are approximate, the comparison of scatter diagrams is shown in Figure 9. The vehicles run on the same line at different running 


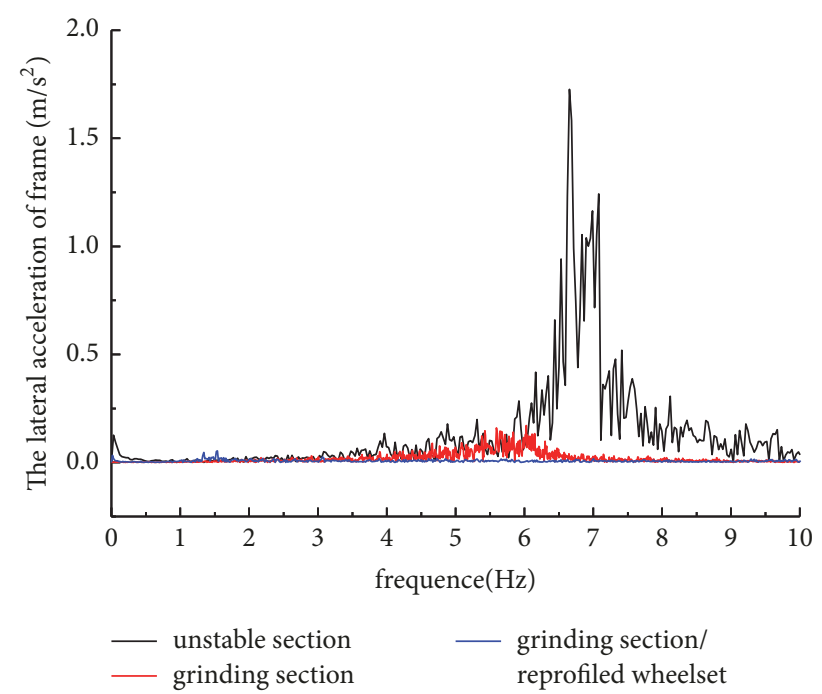

FIGURE 8: The spectrum map of lateral acceleration of bogie frame.

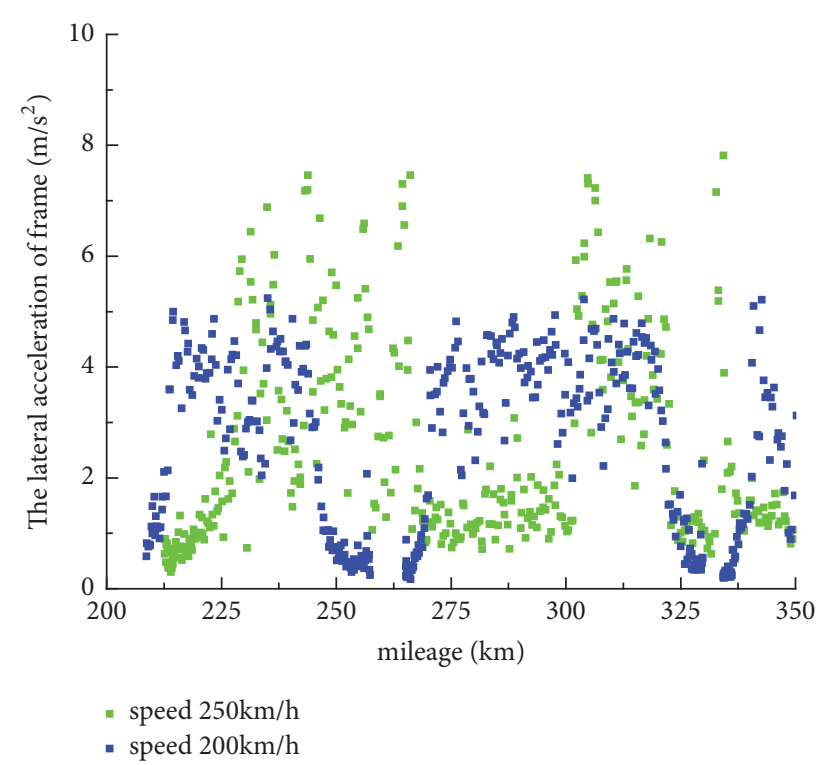

Figure 9: The lateral acceleration scattered plot of bogie frame under different speeds.

speed stages. In detail, for vehicle A, the operation mileage after reprofiling is $184,000 \mathrm{~km}$; the running speed is 200 $\mathrm{km} / \mathrm{h}$. For vehicle $B$, the operation mileage after reprofiling is $190,000 \mathrm{~km}$; the running speed is $250 \mathrm{~km} / \mathrm{h}$. For frames at different speed stages, the comparison of lateral acceleration waveform diagrams is shown in Figure 10. On the basis of the above figures, it can be seen that, for Harbin-Dalian highspeed railway line at a speed of $250 \mathrm{~km} / \mathrm{h}$, the maximum lateral acceleration of bogie frame is $8.1 \mathrm{~m} / \mathrm{s}^{2}$; the average is $2.3 \mathrm{~m} / \mathrm{s}^{2}$. At a speed of $200 \mathrm{~km} / \mathrm{h}$, the maximum is $5.2 \mathrm{~m} / \mathrm{s}^{2}$; the average is $1.7 \mathrm{~m} / \mathrm{s}^{2}$. For the lateral acceleration of bogie frame in Section K200-K350, the waveform diagram at a speed of $250 \mathrm{~km} / \mathrm{h}$ is obviously larger than that at a speed of $200 \mathrm{~km} / \mathrm{h}$.

Table 2 shows the matching equivalent conicities between different worn rails and treads. In the section of gauge corner wear, the wheel-rail matching equivalent conicity is relatively

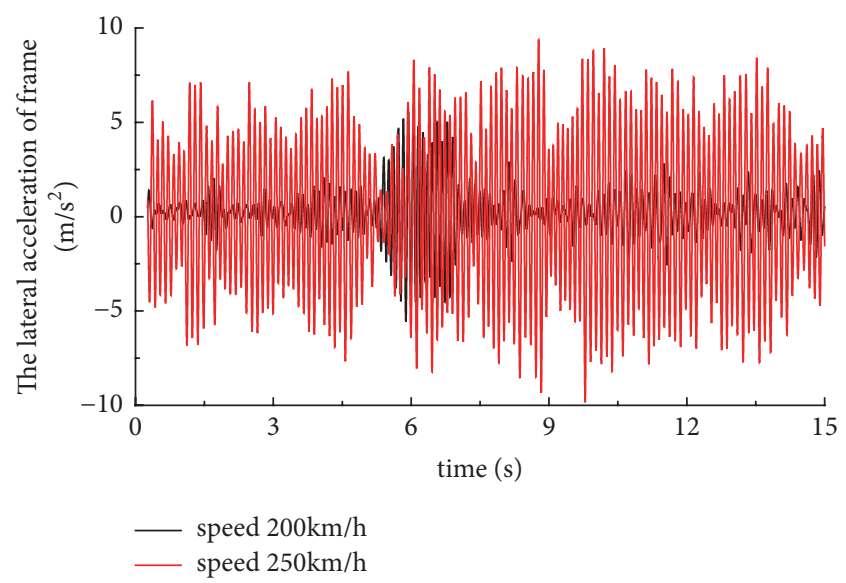

FIGURE 10: The lateral acceleration oscillogram of bogie frame under different speeds.

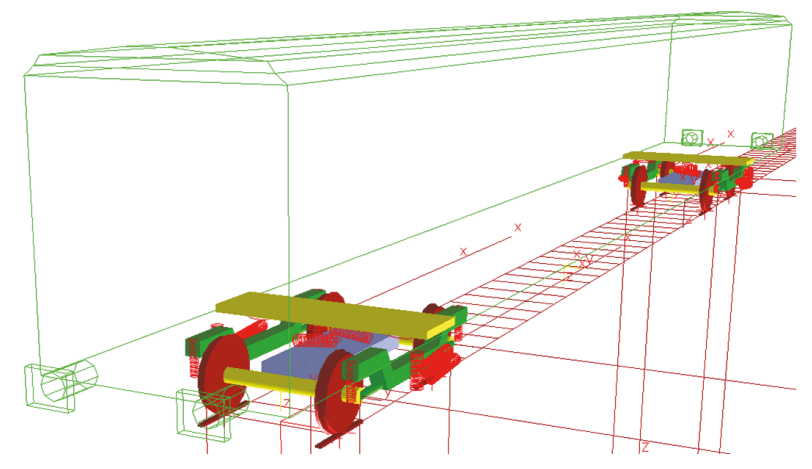

FIGURE 11: Multibody dynamics model of high-speed vehicle.

large, that is, the matching value with new wheels is 0.07 ; the measured value, however, reaches 0.41 , which can cause the lateral instability of bogie frame. The matching equivalent conicity between nongrinded rails (except the rails with gauge corner wear) and measured wheels is 0.31 ; that with new wheels is 0.05 . The matching equivalent conicity between grinded rails and measured wheels is 0.25 ; that with new wheels is 0.05 .

\section{Dynamics Simulation}

4.1. Dynamics Model. In order to find the reason for the bogie frame lateral instability for the high-speed vehicle, the relevant dynamics model was developed (Figure 11) with the help of multibody system software SIMPACK. The model consists of one car body, two bogie frames, two bolsters, four wheel sets, and four gearboxes. The primary suspension includes the primary steel coil spring, the vertical damper, and the axle-box rocker arm positioning device; the secondary suspension includes the air spring, the antirolling torsion bar, the lateral damper, the vertical damper, the antihunting damper, the lateral limit stop, and the Z-shaped traction rod. The nonlinear characteristics of dampers, lateral limit stops, etc. are taken into consideration. The vehicle has a total of 110 degrees of freedom. The working condition for 
TABLE 2: The matching equivalent conicities between different worn rails and treads.

\begin{tabular}{lccccc}
\hline Wheel tread profile & Rail 60 & K865 +350 & Rail profile & & \\
& K884 + 250 & K884+650 & K885+000 \\
& Standard rail & Normal wear of rail tread & Gauge corner wear of rail & Wide tread wear of rail & Grinded rail \\
\hline concave-worn tread & 0.34 & 0.31 & 0.41 & 0.31 & 0.25 \\
reprofiled tread & 0.05 & 0.05 & 0.07 & 0.05 & 0.05 \\
\hline
\end{tabular}

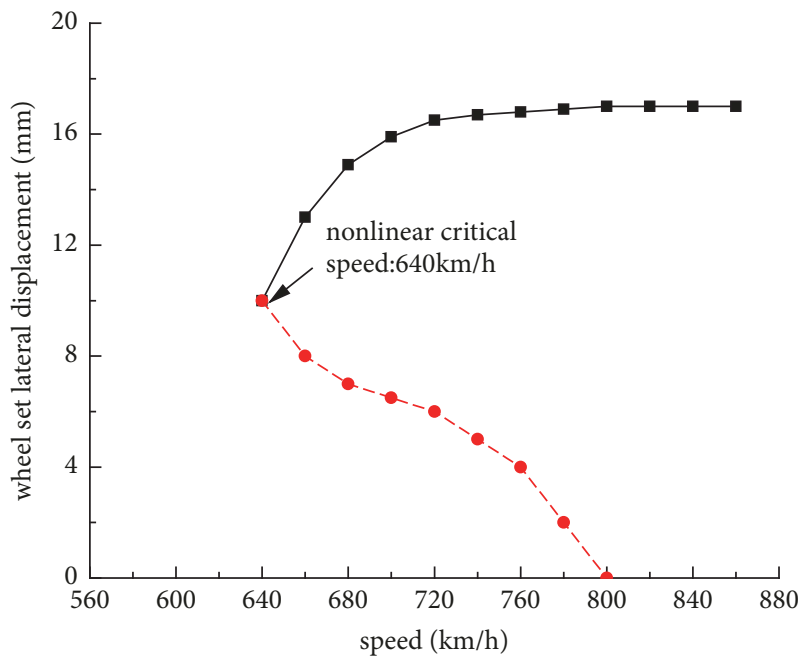

(a) New wheel-new rail

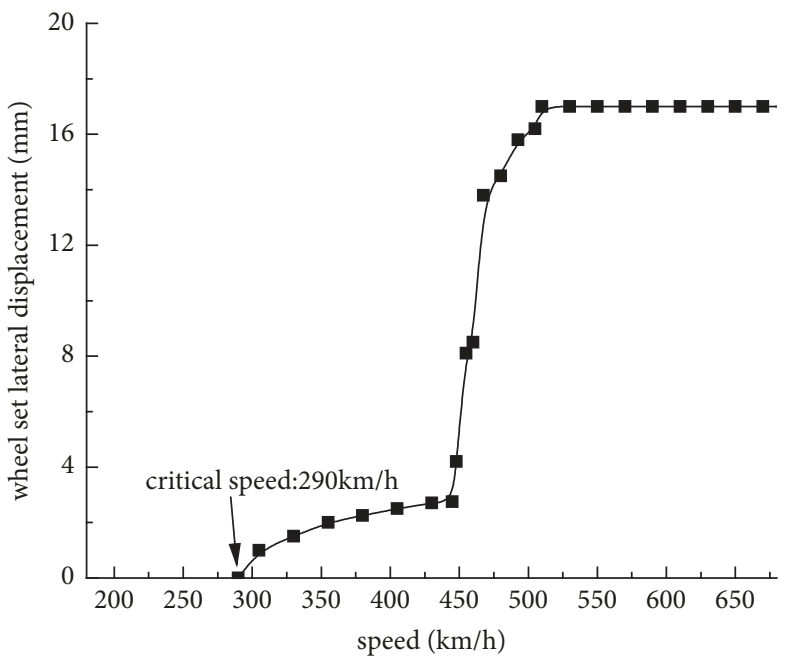

(b) Worn wheel-worn rail

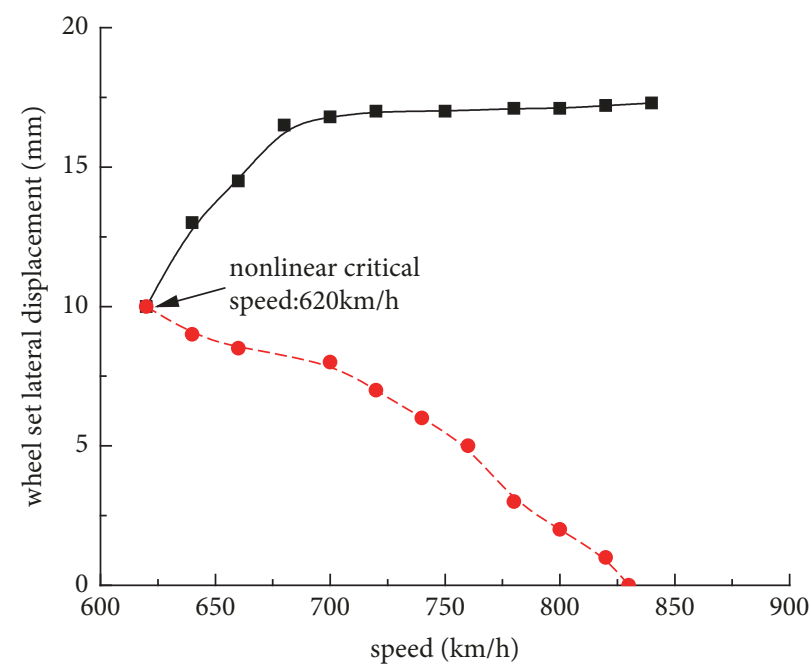

(c) Reprofiled wheel-grinded rail

Figure 12: The effect of wheel-rail wear on nonlinear critical speed.

calculation is the full-load condition; the rolling radius of wheel set is $0.46 \mathrm{~m}$; the rail cant is 1:40; the gauge is $1435 \mathrm{~mm}$; the distance between inner sides of wheel set is $1353 \mathrm{~mm}$; the measured S1002G worn tread is adopted as the wheel tread. For the track excitation, the measured track irregularities are adopted. The operation speed of this vehicle is $250 \mathrm{~km} / \mathrm{h}$, so choose $250 \mathrm{~km} / \mathrm{h}$ as simulation speed in the chapters that follow. The main dynamics parameters of the vehicle are shown in Table 3. Choose the front bogie frame as surveyed object, because under normal condition the acceleration of front bogie frame is larger that of rear one.

\subsection{Dynamics Simulation}

4.2.1. Effect of Wheel-Rail Wear on Vehicle Nonlinear Critical Speed. Nowadays, the sensitivity of wheel-rail wear to the nonlinear critical speed is one of the main subjects for the high-speed wheel-rail technology. Figure 12 shows results for three kinds of wheel/rail wear combinations resulting in different equivalent conicity functions and nonlinear critical speeds. As is shown in the figure, the curve of lateral wheel set displacement represents the stable equilibrium position of wheel set; the wheel set speed curve represents the change 


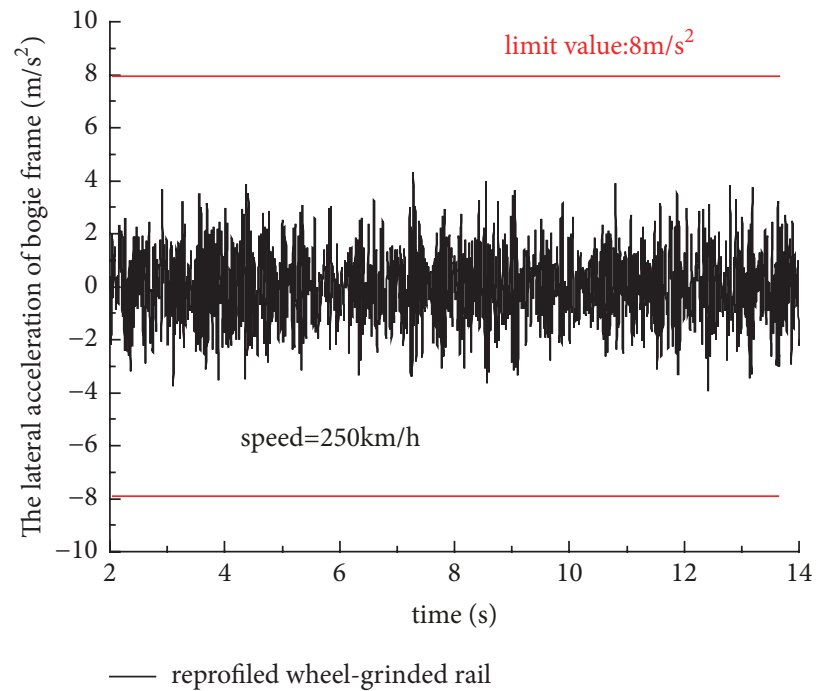

(a) Reprofiled wheel-grinded rail

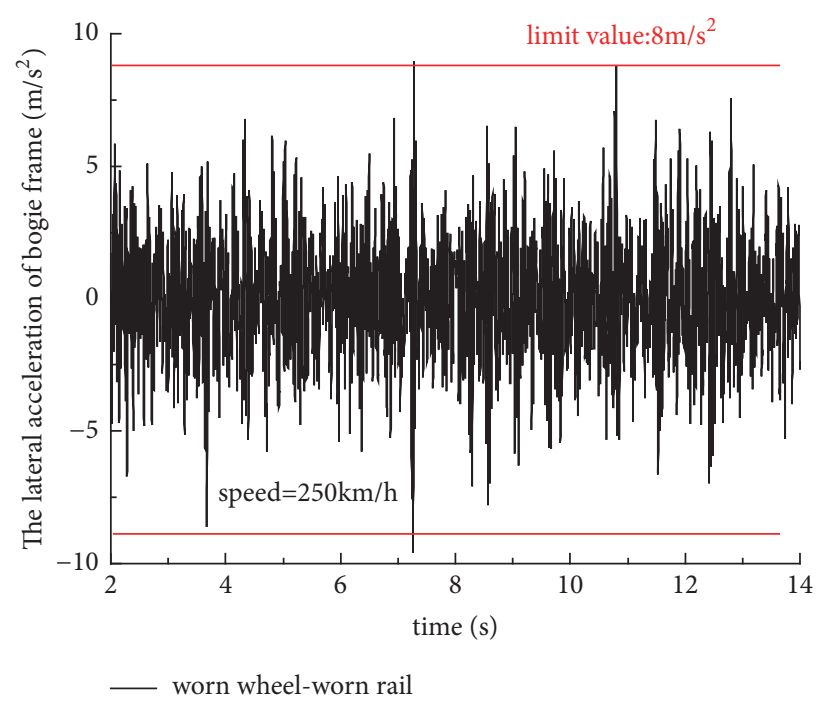

(b) Worn wheel-worn rail

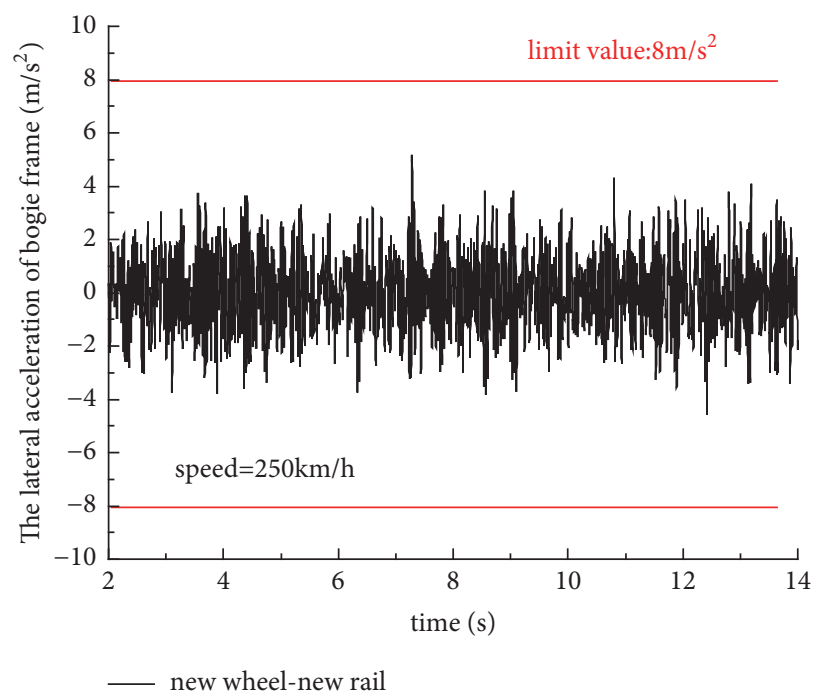

(c) New wheel-new rail

FIgURE 13: The lateral acceleration of bogie frame.

of running speed. The no-liner critical speed calculation method chosen in this paper is put forward by Polach $\mathrm{O}$ [8]. In Figure 12(a), the nonlinear critical speed of bogie with new wheel/rail case reaches $640 \mathrm{~km} / \mathrm{h}$; in Figure 12(b), the nonlinear critical speed of bogie with concave-worn-tread wheel set reaches $290 \mathrm{~km} / \mathrm{h}$; in Figure 12(c), the nonlinear critical speed of bogie with reprofiled tread reaches $620 \mathrm{~km} / \mathrm{h}$. The operation stability of bogie with concave-worn tread and worn rail is significantly reduced; the nonlinear critical speed is about $54.7 \%$ lower than that with new wheel/rail case.

\subsubsection{Effect of Wheel-Rail Wear on Lateral Stability of Bogie} Frame. The method of bogie frame lateral acceleration, which is explained in the standard: «Testing of High-Speed Electric Multiple Unit on Completion of Construction» [22], was adopted to evaluate the effect of the worn wheel profile on the vehicle lateral stability. In Figure 13, the bogie frame lateral acceleration changes with time under three-wheel/rail profile combinations (with the reprofiled wheel set/ grinded rail, the worn tread (the operation mileage is $200,000 \mathrm{~km}$ )/worn rail, and the new wheel/new rail, respectively) are shown. According to the above national standard, the bogie frame lateral acceleration of the new wheel/rail case and that of the reprofiled-grinded wheel/rail case are both within the limit of the specified value. When the operation mileage is more than $200,000 \mathrm{~km}$, however, the lateral acceleration exceeds the specified value, which indicates that the bogie frame matches the instability condition.

\subsubsection{Effect of Wheel-Rail Wear on Vibration Characteristics} of Car Body and Wheel Set. Figure 14 shows the change of lateral acceleration with time; Figure 15 shows the change of lateral displacement with time. It can be seen from the figures that, compared with the new wheel/rail profiles, the 
TABLE 3: The main parameters of vehicle.

\begin{tabular}{|c|c|c|c|}
\hline Parameter & Value & Parameter & Value \\
\hline car body mass/t & 39 & Wheel set mass/t & 1.6 \\
\hline frame mass/t & 2.3 & bolster mass/t & 1.8 \\
\hline bolster mass/t & 0.7 & $\begin{array}{l}\text { bolster inertia } \\
\text { moments/(kg.m2) }\end{array}$ & $450 / 60 / 500$ \\
\hline $\begin{array}{l}\text { car body rotational } \\
\text { inertia/(kg.m2) }\end{array}$ & $96000 / 1700000 / 1650000$ & $\begin{array}{l}\text { wheel set rotational } \\
\text { inertia/(kg.m2) }\end{array}$ & $800 / 140 / 800$ \\
\hline $\begin{array}{l}\text { frame rotational } \\
\text { inertia/(kg.m2) }\end{array}$ & $2100 / 2600 / 4000$ & $\begin{array}{l}\text { gearbox rotational } \\
\text { inertia/(kg.m } 2)\end{array}$ & $190 / 1300 / 1400$ \\
\hline $\begin{array}{l}\text { length between bogie } \\
\text { pivot centers } / \mathrm{m}\end{array}$ & 17.375 & wheelbase/m & 2.5 \\
\hline $\begin{array}{l}\text { primary suspension } \\
\text { three direction } \\
\text { rigidity } /(\mathrm{MN} / \mathrm{m})\end{array}$ & $120 / 12 / 0.9$ & $\begin{array}{l}\text { secondary suspension } \\
\text { three-direction } \\
\text { rigidity } /(\mathrm{MN} / \mathrm{m})\end{array}$ & $0.12 / 0.12 / 0.18$ \\
\hline
\end{tabular}

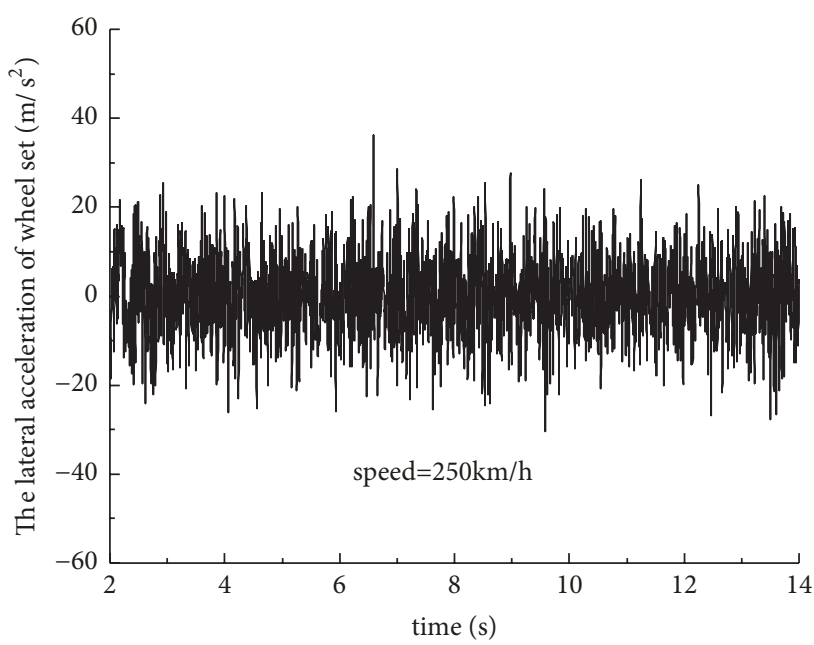

— reprofiled wheel-grinded rail

(a) Reprofiled wheel-grinded rail

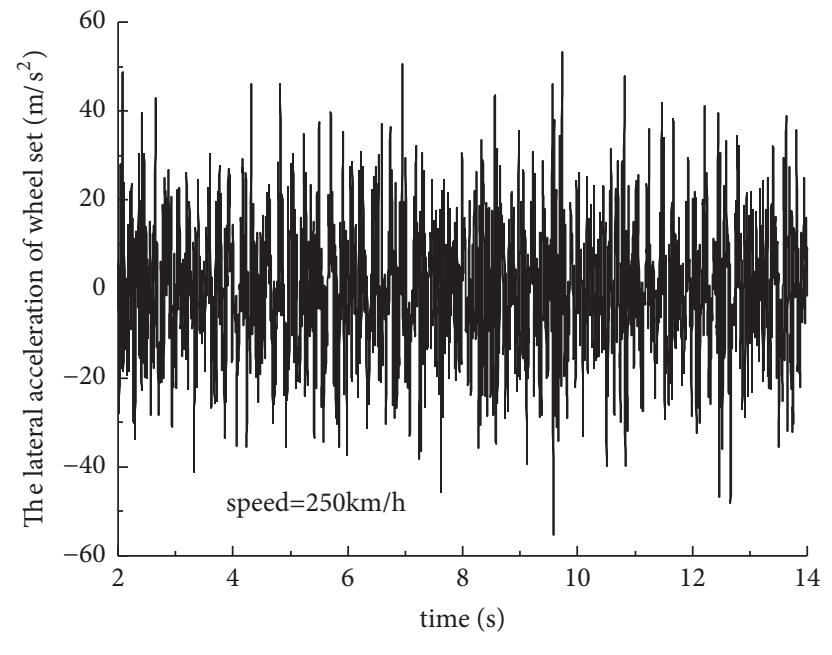

— worn wheel-worn rail

(b) Worn wheel-worn rail

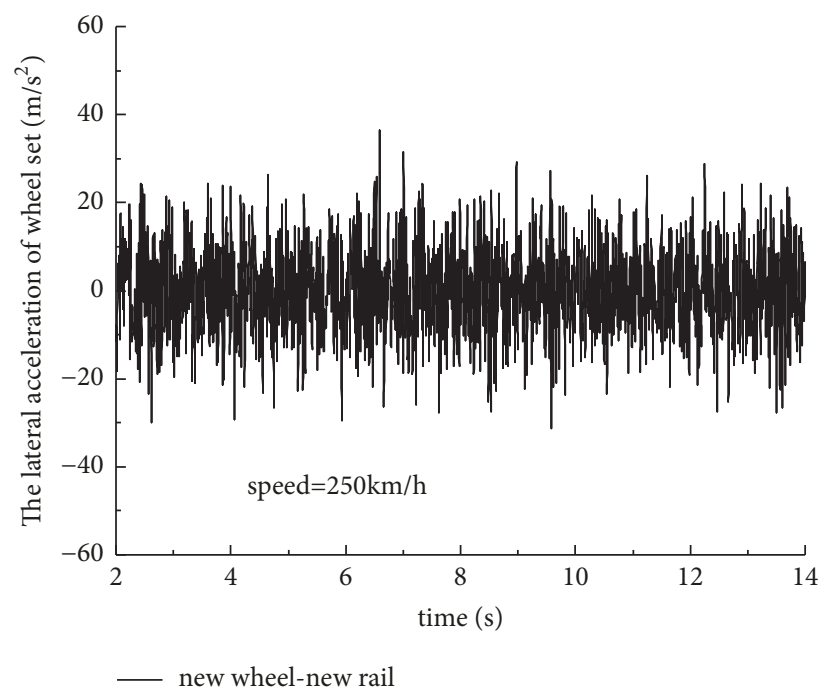

(c) New wheel-new rail

FIgURE 14: The lateral acceleration of wheel set. 


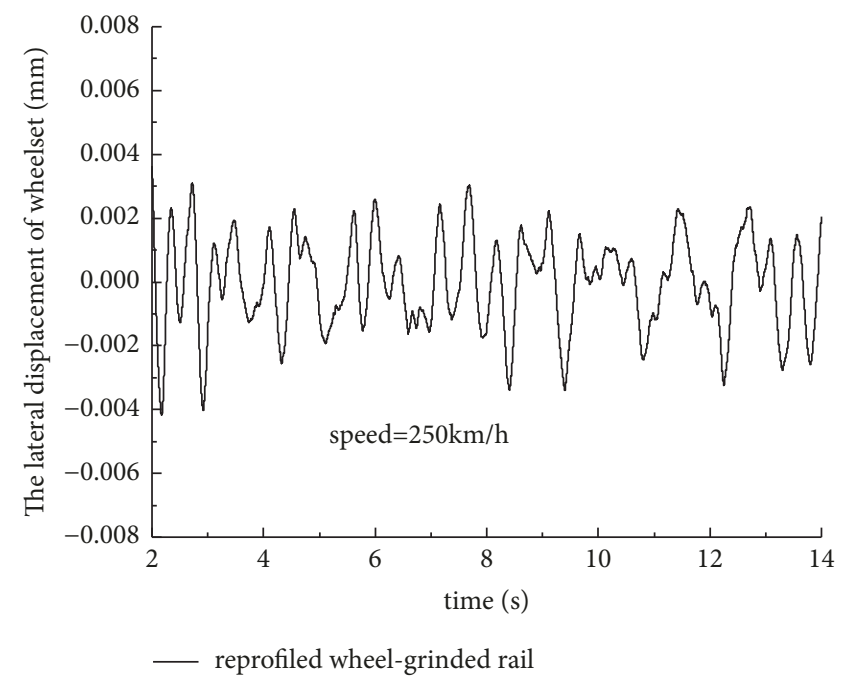

(a) Reprofiled wheel-grinded rail

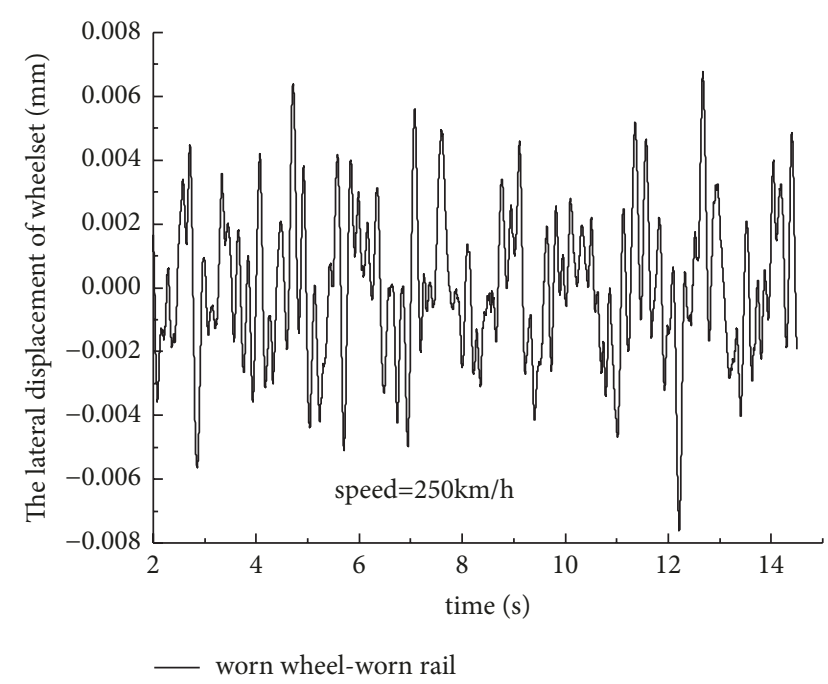

(b) Worn wheel-worn rail

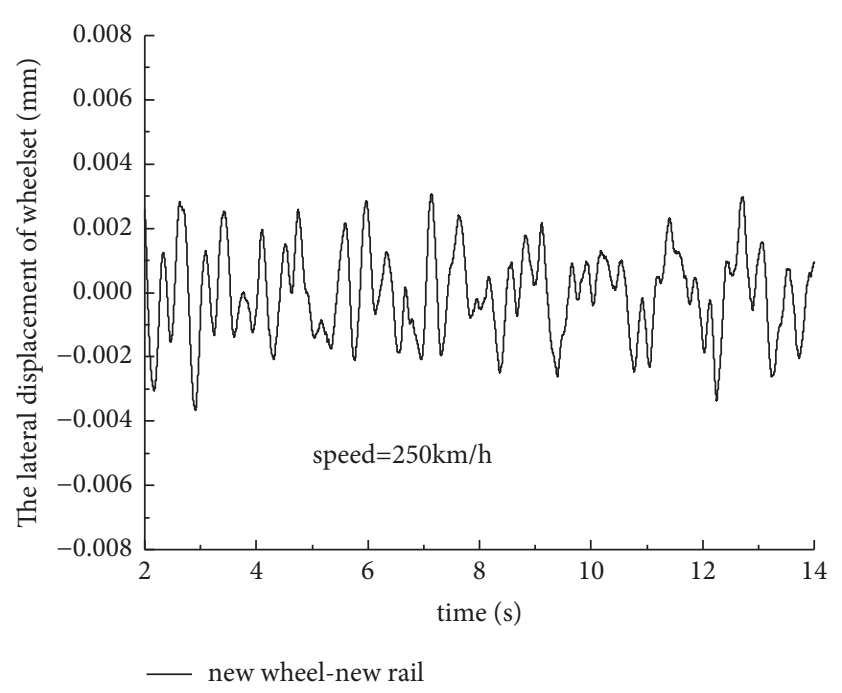

(c) New wheel-new rail

FIGURE 15: The lateral displacement of wheel set.

acceleration of wheel set with measured worn wheel/rail case significantly increases; with that kind of wheel set, the flange contacts the rails, and the lateral wheel/rail impact force is larger; that is, the wheel set motion instability appears. The lateral vibration acceleration of wheel set with grindedreprofiled wheel/rail case significantly decreases, which is almost reduced to the range of the new wheel/rail case. It turns out that the wheel/rail wear is the important cause for the vehicle lateral instability.

Figure 16 shows waveform diagram of vehicle body vibration acceleration; Figure 17 shows the power spectral density of bogie frame and car body lateral acceleration for worn wheel and rail as well as spectra of lateral wheel set force. According to the two figures, the vibration acceleration of car body significantly increases as well with the lateral wheel set force. The main frequency of lateral vibration for the car body and the bogie frame is between 4 and $7 \mathrm{~Hz}$, which is identical to that of wheel/rail force. Consequently, it can be reached that the wheel/rail impact excites the lateral vibration of car body and bogie frame, and meanwhile it causes the bad performance of vehicle lateral operation.

\section{Conclusion}

(a) By a field investigation about the unstable vehicle, it is found that different levels of wheel concave wear appear on the wheels of alarming bogie frame. By measuring the rail profiles in the unstable section, the rail profiles in the alarming section are mainly that of wide-worn-tread rail and that of worn-gauge-corner rail, for which the rail has not been grinded for a long time. The comparison of figures indicates that there is a large difference of profiles between the rail which has not been grinded for a long time and the standard rail.

(b) In order to analyze the effect of wheel reprofiling and rail grinding on the lateral acceleration of bogie frame, 


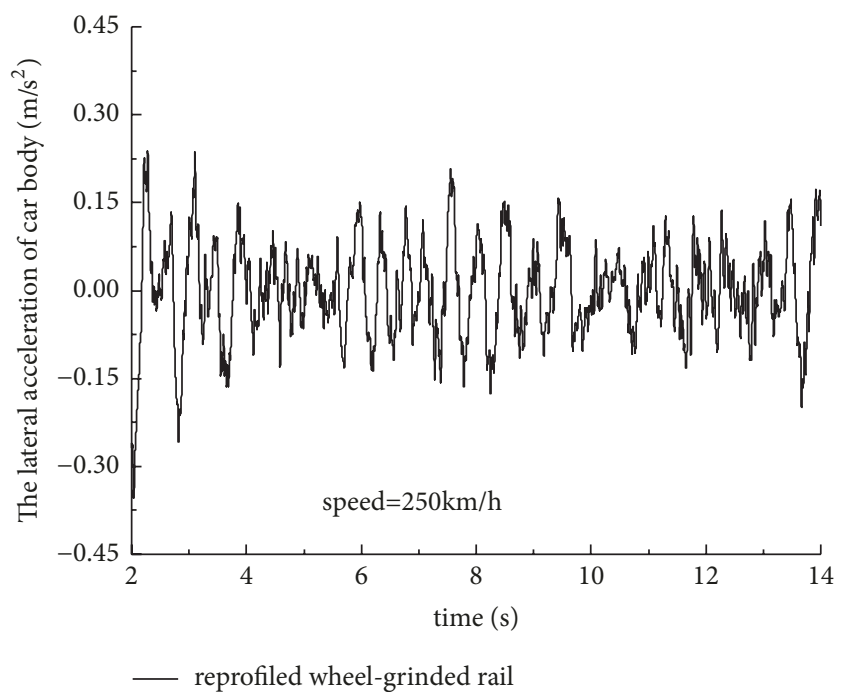

(a) Reprofiled wheel-grinded rail

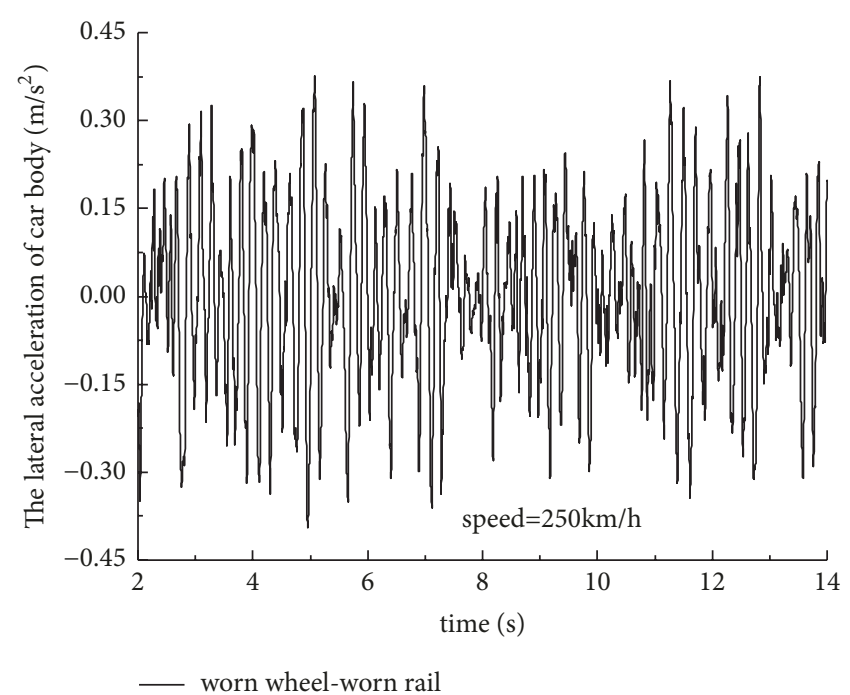

(b) Worn wheel-worn rail

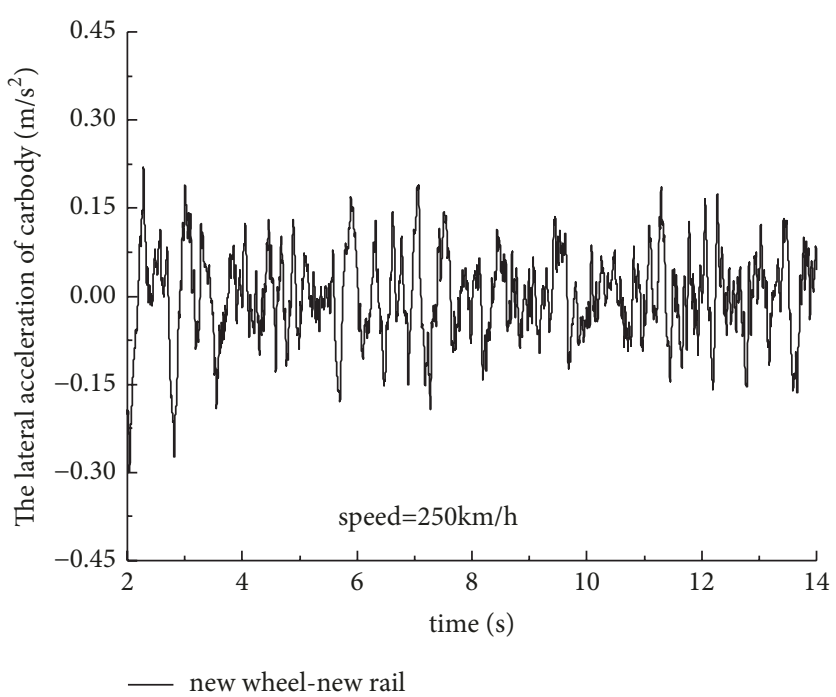

(c) New wheel-new rail

FIgURE 16: The lateral acceleration of car body.

the field tests for the same vehicle are carried out in the grinded-rail section and the neighbouring lateral-unstableframe section. After grinding the rail, the amplitude of bogie frame vibration is obviously restrained, and the amplitude of bogie frame lateral acceleration is very small after the tread reprofiling. In addition, when passing the sections where the rail has not been grinded for a long time, the high-speed vehicle should run at a lower speed.

(c) According to the simulation analysis, it can be reached that the over-standard equivalent conicity which is caused by abnormal wheel-rail wear is the main cause for the lateral instability of bogie frame. For the rail in the alarming section, the rail profile can be restored to the designed profile by grinding, which contributes to the mitigation of bogie frame alarm. When the normal operation of the vehicle is affected by the abnormal tread wear, the wheel set should be reprofiled as soon as possible.
In China, there has not been any special standard to evaluate the equivalent conicity so far. Therefore, relevant researches should be developed in order to establish the reprofiling and grinding standards for different lines and different running speeds, so the maintenance of tread and rail can be reasonably conducted.

The rolling continuity of wheel-rail contacts is an important factor for vehicle operation. While the abnormal wheelrail wears occur, what consequence will be produced in the wheel-rail contacts is an interesting field, we may move on to that field and conduct the bulk of the research.

\section{Conflicts of Interest}

The authors declare that there are no conflicts of interest regarding the publication of this paper. 

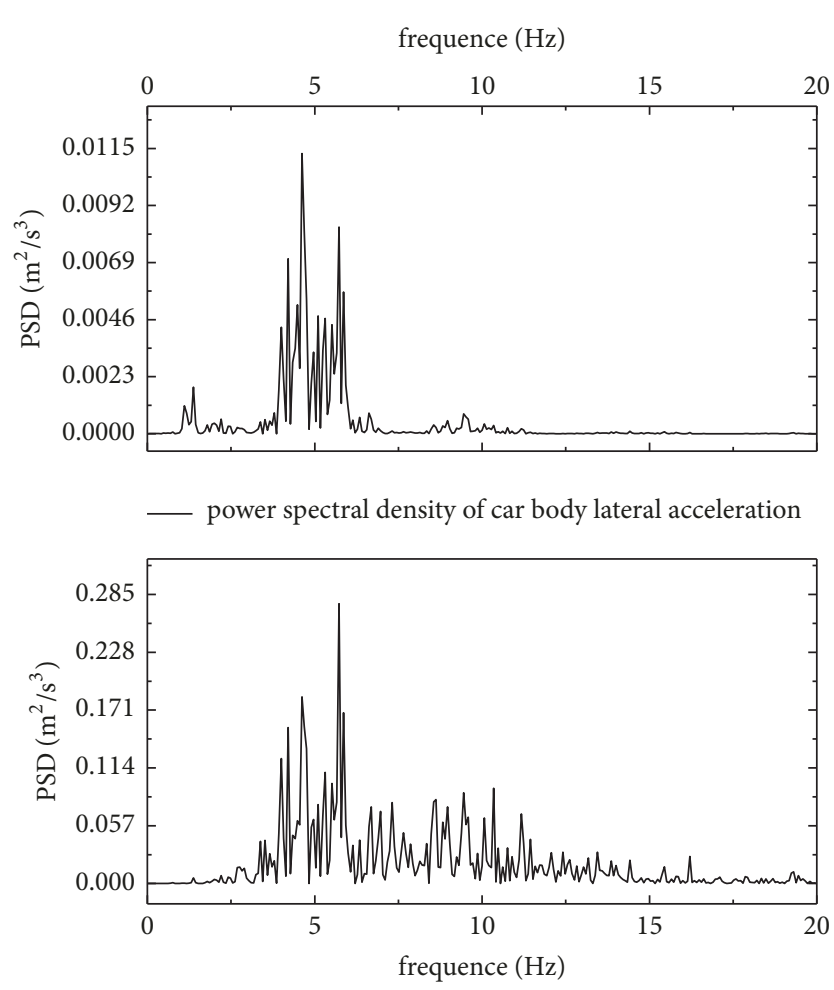

_ power spectral density of frame lateral acceleration

(a) The vehicle acceleration power spectral density
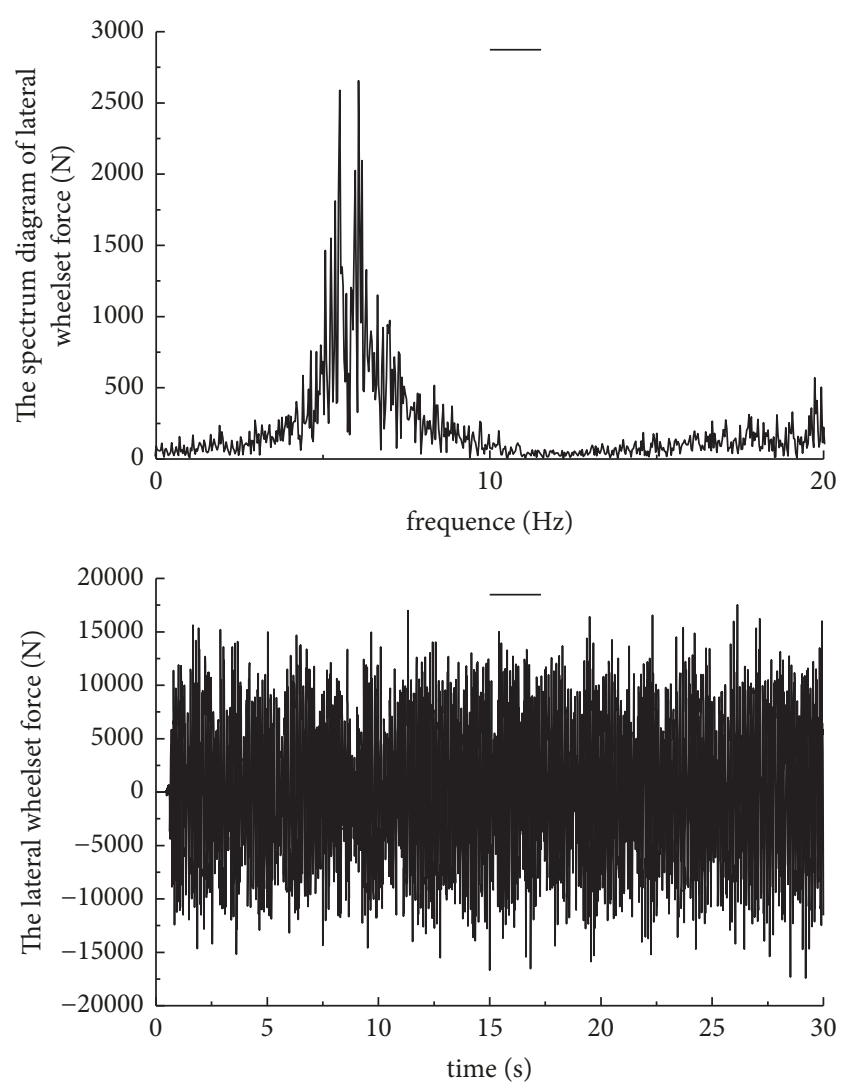

(b) The lateral wheel set force

FIGURE 17: The vehicle acceleration power spectral density and the lateral wheel set force.

\section{Acknowledgments}

The authors are grateful for the grants provided by the National Natural Science Foundation of China (Grant no. 51575458), Doctoral Innovation Fund Program of Southwest Jiaotong University (Grant no. 2014300179), Science and Technology Development Project of Chinese National Railway Corporation (Grant no. 2017J011-B), and China Academy of Railway Science Fund Project (Grant no. 2017YJ009).

\section{References}

[1] T. Guangrong, "Evaluation Limit for Hunting Instability of Railway Freight Train," China Railway Science, vol. 37, no. 5, pp. 87-93, 2016.

[2] P. T. Torstensson, A. Pieringer, and J. C. O. Nielsen, "Simulation of rail roughness growth on small radius curves using a nonHertzian and non-steady wheel-rail contact model," Wear, vol. 314, no. 1-2, pp. 241-253, 2014.

[3] D. Cui, L. Li, H. Wang, Z. Wen, and J. Xiong, "High-speed EMU wheel re-profiling threshold for complex wear forms from dynamics viewpoint," Wear, vol. 338-339, pp. 307-315, 2015.

[4] W. Klingel, Uber den Lauf der Eisenbahnwagen auf gerader Bahn[J]. Organ fur die Fortschritte des Eisenbahnwesens, vol. 20, no. 4, pp. 113-123, 1883.

[5] A. H. Wickens, "The dynamic stability of railway vehicle wheelsets and bogies having profiled wheels," International Journal of Solids and Structures, vol. 1, no. 3, pp. 319-341, 1965.
[6] N. K. Cooperrider and J. J. Gordon, "Shock and impact levels on North American locomotives," Journal of Sound and Vibration, vol. 318, no. 4-5, pp. 809-819, 2008.

[7] H. True, "The dynamics of a railway freight wagon wheelset with dry friction damping the suspension," Vehicle System Dynamics, vol. 38, no. 2, pp. 159-168, 2004.

[8] O. Polach, "Wheel profile design for target conicity and wide tread wear spreading," Wear, vol. 271, no. 1-2, pp. 195-202, 2011.

[9] G. Schupp, "Bifurcation analysis of railway vehicles," Multibody System Dynamics, vol. 15, no. 1, pp. 25-50, 2006.

[10] K. Zboinski and M. Dusza, "Analysis and method of the analysis of non-linear lateral stability of railway vehicles in curved track," Vehicle System Dynamics, vol. 41, pp. 222-231, 2004.

[11] Y.-S. Choi and B.-S. Shin, "Critical speed of high-speed trains considering wheel-rail contact," Journal of Mechanical Science and Technology, vol. 29, no. 11, pp. 4593-4600, 2015.

[12] M. Ahmadian and S. Yang, "Effect of system nonlinearities on locomotive bogie hunting stability," Vehicle System Dynamics, vol. 29, no. 6, pp. 365-384, 1998.

[13] J.-H. Park, H.-I. Koh, and N.-P. Kim, "Parametric study of lateral stability for a railway vehicle," Journal of Mechanical Science and Technology, vol. 25, no. 7, pp. 1657-1666, 2011.

[14] Q. Zhou, C. Tian, Y. Zhang, C. Chang, and M. Hou, "Cause analysis for the lateral instability of CRH3 EMU framework," Zhongguo Tiedao Kexue/China Railway Science, vol. 35, no. 6, pp. 105-110, 2014. 
[15] L. Sun, Evaluation Method Study and Theory Analysis of of Lateral Running Stability and Dynamics Derailment of High Speed, China of Railway Sciences, 2014.

[16] S. Liang, M. Piao, X. Zhang, and W. Zhao, "Investigation of Nonlinear Effects on High-speed Vehicle Lateral Stability," Journal of the China Railway Society, vol. 5, pp. 23-30, 2009.

[17] M. Piao, S. Liang, Z. Fang, and W. Zhao, "The non-linearity of high-speed bogie and the safety stability margin of highspeed railway vehicles," Zhongguo Tiedao Kexue/China Railway Science, vol. 32, no. 3, pp. 86-92, 2011.

[18] X.-H. Zeng, H. Wu, J. Lai, and Y. Yu, "The effect of wheel set gyroscopic action on the hunting stability of high-speed trains," Vehicle System Dynamics, vol. 55, no. 6, pp. 924-944, 2017.

[19] F. Gan, H. Dai, H. Gao, and M. Chi, "Wheel-rail wear progression of high speed train with type S1002CN wheel treads," Wear, vol. 328-329, pp. 569-581, 2015.

[20] O. Polach, "Wheel profile design for the targeted conicity and a wide contact spreading," in Proceedings of the International Conference on Contact Mechanics and Wear of Rail/wheel Systems, 2009.

[21] K. D. Van and M. H. Maitournam, "Rolling contact in railways: Modelling, simulation and damage prediction," Fatigue \& Fracture of Engineering Materials \& Structures, vol. 26, no. 10, pp. 939-948, 2003.

[22] TB 17061-2013, Testing of High-speed Electric Multiple Unit on Completion of Construction. 


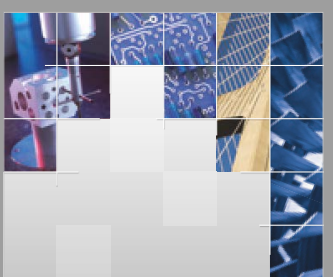

\section{Enfincering}
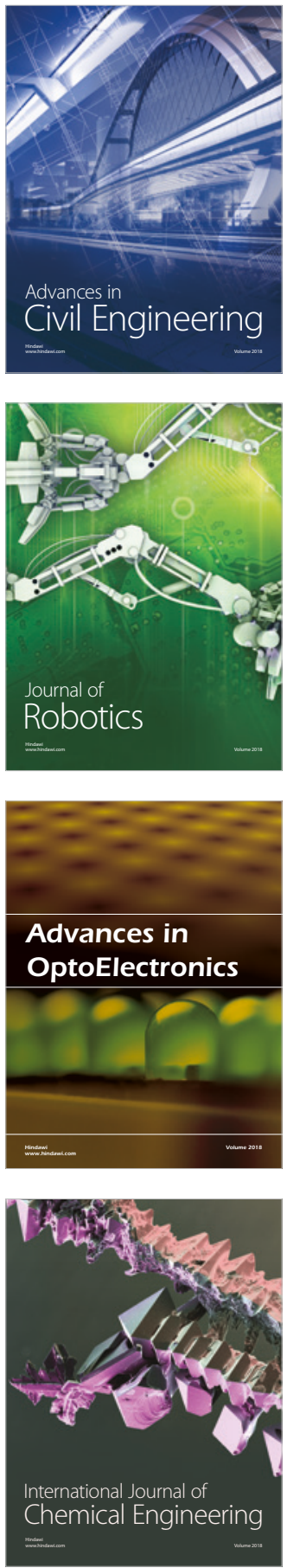

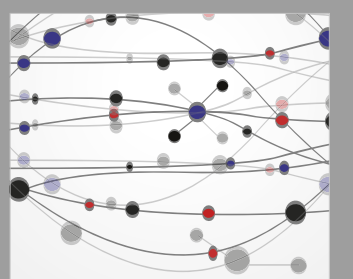

\section{Rotating \\ Machinery}

The Scientific World Journal

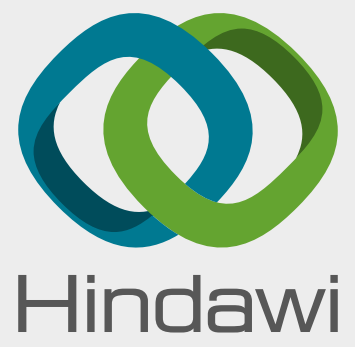

Submit your manuscripts at

www.hindawi.com
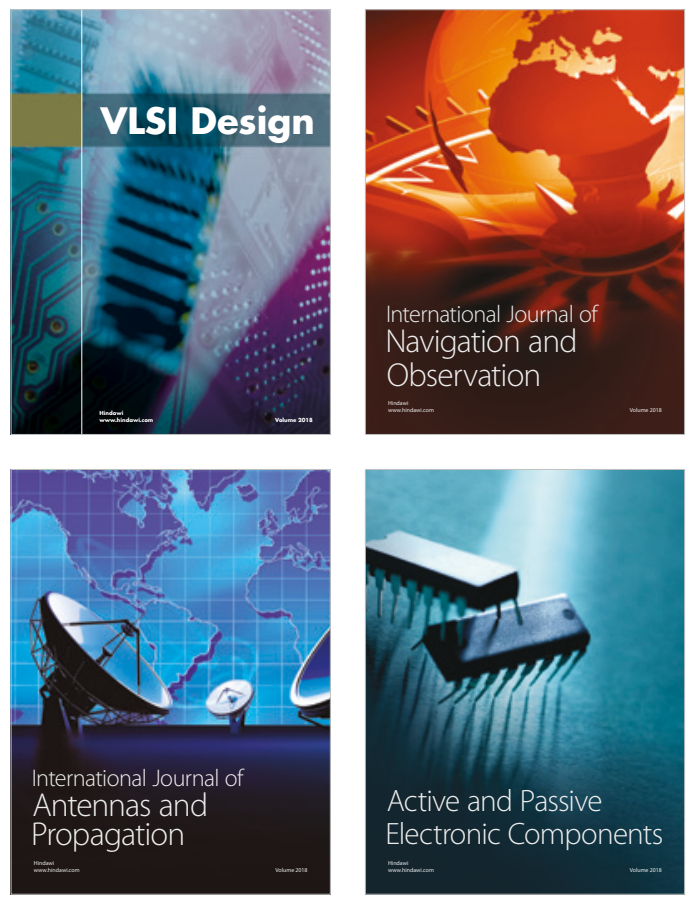
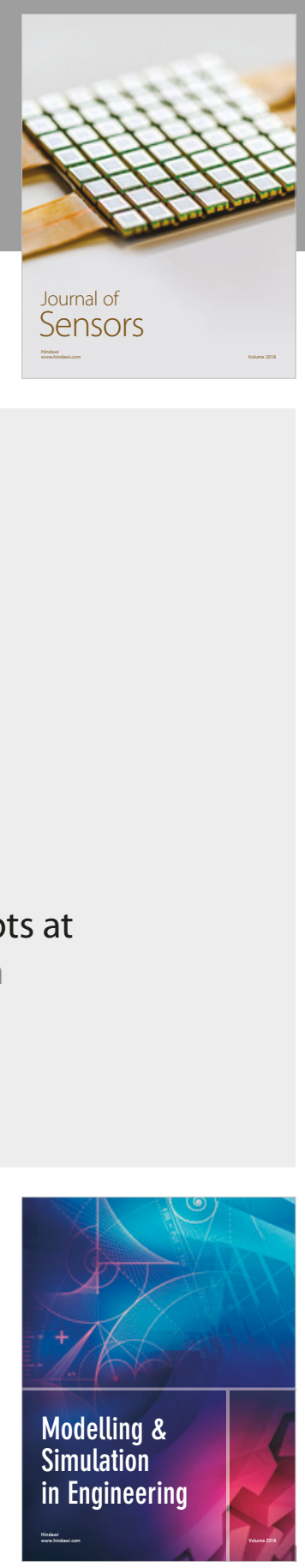

\section{Advances \\ Multimedia}
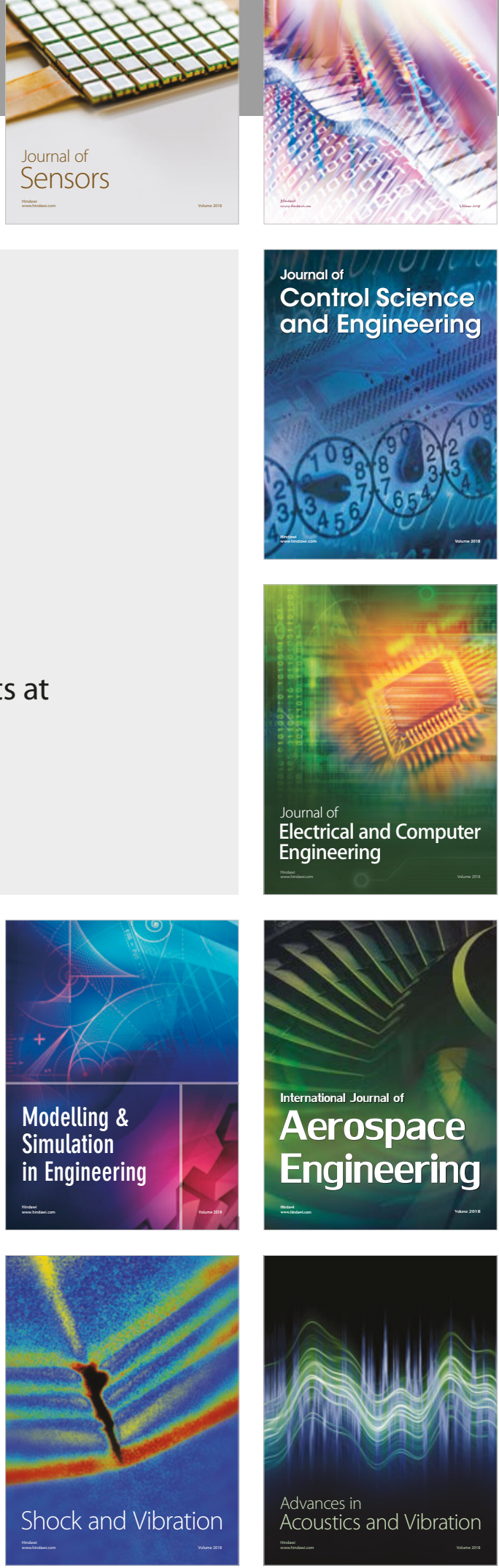